\title{
Infrações no trânsito: uma necessária distinção entre erros e violações
}

\author{
João Bosco de Assis Rocha \\ Universidade Federal do Pará
}

\begin{abstract}
RESUMO
Alguns milhões de infrações são cometidas no trânsito a cada ano no Brasil, resultando em milhares de mortes, feridos e prejuízos materiais. Somente nos últimos anos, entretanto, surgiu um crescente interesse dos estudiosos do comportamento humano no trânsito pelo entendimento da infração e a sua etiologia. Os erros, diferentemente das violações que são caracterizadas pelas ações deliberadas, como avançar sinal vermelho, por exemplo, são influenciadas pelo contexto socioeconômico e relacionamse com os processos cognitivos do indivíduo. Poder-se-ia dizer que, na violação, ocorre uma escolha consciente, enquanto, no erro, a opção aparece como única ou correta. Supõe-se que o conhecimento da etiologia e a distinção entre as modalidades de infrações poderão possivelmente proporcionar um melhor direcionamento das ações das autoridades e educadores nas questões do trânsito.
\end{abstract}

Palavras-chave: erros; violações; trânsito.

\section{ABSTRACT \\ Traffic infractions: a necessary distinction between errors and violations}

Millions of infractions are committed by drivers in Brazil every year, resulting in thousands of personal injuries, deaths, and material damages. However, only in recent years there has been an increased interest in human traffic behavior and studies to understanding the infraction and its etiology. Errors, differently from violations that relate to intentional actions as, for example, running the red traffic light, relate to the individual cognitive process. Violations are influenced by socioeconomic context. It could be said that during violation cases there is a conscious choice, while in the error cases the option it appears as only option or the correct one. In this work it was supposed that the knowledge of etiology and the distinction between infraction types might be able to improve educators and authorities actions concerning traffic issues.

Keywords: errors; violations; traffic.

Em qualquer lugar do mundo, pelo que sabemos, quando um motorista avança um sinal vermelho, uma infração é cometida. As autoridades, entretanto, parecem não se preocupar ou se sentem impotentes em distinguir se este ato é cometido devido a alguma dificuldade cognitiva do condutor ou se é por causa de alguma ação deliberada sua. Conhecer a etiologia de um comportamento desta natureza parece ser coisa impossível, mas, considerando os avanços tecnológicos das ciências comportamentais e cognitivas, nos permitimos idealizar ou pelo menos sonhar com alguma forma de num futuro registrar as intenções e ações dos motoristas, à semelhança das chamadas "caixas pretas" das aeronaves, que revelam as operações realizadas pelos pilotos durante um vôo. Mas, enquanto este aparato não chega, os erros e as violações permanecem num mesmo rol, indistintos, sem se desvendar as suas verdadeiras causas. Assim sendo, instituições e autoridades de controle do trânsito deixam de proporcionar tratamento adequado aos infratores, seja do ponto de vista pedagógico, jurídico ou psicológico. Por outro lado, felizmente, um considerável acervo literário vem se desenvolvendo, fruto de crescente interesse por pesquisas em torno do tema erros e violações, fazendo-nos supor que a ciência poderá indicar um caminho para melhor entender e lidar com essas questões.

Este artigo não tem a intenção de analisar ou rever os conceitos sobre os termos "infração", "erro" e "violação" e seus usos, mas pretende, a partir do conhecimento já acumulado na literatura em torno desses assuntos, levantar uma questão pouco discutida que é distinguir erros e violações nas normas de trânsito adequadamente e tratar de forma diferente os motoristas que infringem as normas por erro daqueles que as infringem intencionalmente. Assim como na prática médica, em que o diabetes e a esquizofrenia, que são doenças com etiologias próprias, os portadores destes males além de serem medicados precisam de re-educação alimentar (não consumindo açúcar e bebidas alcoólicas), para que o tratamento possa ser bem sucedido. Se os diabéticos e os esquizofrênicos fossem tratados de forma genérica, recebendo medicamentos e re-educação não específicos para cada caso, o tratamento seria inócuo, não curando nem amenizando seus males. 
Seguindo esta linha de raciocínio, parece-nos lógico imaginar que se fosse dado tratamento adequado aos motoristas, análogo ao que é dado aos doentes, possivelmente menos infrações seriam registradas e a saúde do trânsito poderia ser melhor.

A literatura tem mostrado que a distinção entre erros e violações, definida por Reason, Manstead, Stradling, Baxter e Campbell (1990), é aceita por vários pesquisadores como, Blockey e Hartley (1995); Parker, Reason, Manstead e Stradling (1995); Aberg e Rimmö (1998); Westerman e Haigney (2000), Kontogiannis, Kossiavelou e Marmaras (2002), dentre outros. Por outro lado, pouca discordância quanto à distinção é encontrada, conforme assinala Monteiro (2004), a qual se refere somente a Groeger (1990) como um discordante. Muito embora tenhamos afirmado que não é intenção deste artigo focalizar questões conceituais sobre erro e violação, é oportuno para o foco deste artigo citar o posicionamento de vários autores. Monteiro (2004) sustenta a discordância de Groeger quanto à distinção entre os dois termos, quando afirma: "ambos podem produzir resultados indesejados" (Monteiro, 2004, p. 23). Ora, os resultados podem ser os mesmos, mas produzidos por processos diferentes, ou seja, errando ou violando o motorista comete infração. Acreditamos que nessa discussão, tanto a nossa neste artigo quanto a de Monteiro, o que mais importa são as causas do erro e da violação, sendo reconhecidas como diferentes na literatura quanto às suas origens, mas produzindo resultados indesejados iguais.

No artigo publicado por Reason e cols. (1990), Errors and violations on the roads: a real distinction?, que tem sido referência para discussões sobre erros e violações, os autores levaram em conta em primeiro lugar o fato da contribuição humana para o acidente e consideraram necessário fazer distinção entre os dois termos como duas formas inadequadas de comportamento em relação às regras de trânsito, que, segundo eles, têm "origens psicológicas diversas que requerem diferentes maneiras de correção" (p. 1315). Na pesquisa realizada por Reason e cols. (1990), quinhentos e vinte condutores responderam a um questionário, o DBQ - Driver Behaviour Questionnaire, em que foram solicitados a avaliar a frequiência com que cometiam vários tipos de erros e violações enquanto dirigiam. Três fortes fatores foram identificados: violações, erros perigosos e deslizes relativamente inofensivos. A freqüência das violações diminuiu com a idade, os erros não. Homens de todas as idades registraram mais violações do que as mulheres, entretanto estas foram significativamente mais propensas a cometer erros inofensivos, ou foram mais honestas do que os homens admitindo-os, assinalam os autores. Estes achados foram coerentes com a visão de que erros e violações estão relacionados a diferentes mecanismos psicológicos. Violações requerem explicações relacionadas com fatores motivacionais e sociais, enquanto que erros com características de processamento de informação pelo indivíduo.

O estudo de Reason e cols. (1990) iniciou uma fase importante na busca do entendimento das causas dos acidentes e das diferenças entre erros e violações. Anteriormente havia um consenso de que os fatores humanos estivessem presentes em grande parte dos acidentes, conforme já assinalavam Sabey e Taylor (1980), citados por Reason e cols. (1990), muito embora não fosse fácil estabelecer clara relação entre comportamento inadequado às regras de segurança de trânsito e responsabilidade por acidentes. O estudo desenvolvido por Reason e cols. (1990) - o primeiro de uma série - não pretendeu estabelecer qualquer conexão entre as variedades de comportamentos inadequados e suas responsabilidades em acidentes. "A nossa primeira preocupação foi com a possível distinção entre comportamentos inadequados", assinalam Reason e cols. (1990, p. 1317).

O instrumento usado na pesquisa citada - o DBQ continha 50 itens selecionados para abranger cinco categorias de comportamentos inadequados às regras de segurança de trânsito. Os deslizes, cujos exemplos seriam interpretar uma placa de sinalização incorretamente e entrar numa via errada ou ligar os faróis, quando a intenção fosse acionar os limpadores de pára-brisa. Os lapsos, bons exemplos seriam não lembrar de uma via recentemente percorrida ou aguardar a abertura do sinal verde na terceira marcha. Os Erros, cujo exemplo seria subestimar a velocidade de um veículo em sentido contrário, quando vai ultrapassar. Dirigir com o seguro obrigatório e o imposto viário vencidos ou constatar no marcador de velocidade do veículo que está além do limite de velocidade permitido, constituiriam violações não intencionais. Finalmente, as violações deliberadas podem ser exemplificadas por situações em que um motorista torna-se impaciente com um veículo vagaroso à sua frente, ultrapassando-o de forma errada pela direita.

Na discussão e conclusão da sua pesquisa, Reason e cols. (1990) afirmam que o comportamento de dirigir é extremamente complexo e nenhum método de investigação pode captar todas as suas implicações. Embora os questionários auto respondidos, como o DBQ, revelem comportamentos normalmente muito particulares para serem detectados por observação direta, eles podem "na melhor das hipóteses produzir avaliações de frequiência ordinais baseadas em impressões passadas subjetivas de direção" (Reason \& cols. 1990, p. 1330).

Uma das afirmações que consideramos importante, feita pelos autores na conclusão do artigo sobre a pesquisa, sintetiza bem os seus achados: "A análise fato- 
rial fez uma distinção muito clara entre erros perigosos e violações. Por si só, naturalmente, estes achados não constituem evidência sólida de uma separação entre seus processos psicológicos subjacentes, mas é certamente consistente uma possibilidade como essa" (Reason \& cols., 1990, p. 1330), mas por outro lado os pesquisadores não tecem mais comentários a respeito, fazendo supor, no nosso entender, que tal assertiva carece de melhor investigação. Acrescentam ainda os autores que a idéia de que erros e violações representam diferentes espécies de comportamentos inadequados às regras do trânsito, torna-se ainda mais acentuada quando se observam os dados obtidos nas pesquisas relacionados com idade e sexo. Por exemplo, as violações declinam com a idade, mas os erros não e os homens de todas as idades registram mais violações do que as mulheres. Outras considerações feitas por Reason e cols. (1990), na conclusão do seu artigo, fazem referências às diferenças entre homens e mulheres ao dirigir, citando, por exemplo, que há mais tendência por parte das mulheres cometer mais erros, mas esta ocorrência só foi significativa em se tratando de lapsos inofensivos. Esses dados de Reason e cols. (1990) parecem estar em consonância com os achados de Storie (1977), os quais consideram que as mulheres cometem mais erros de natureza perceptual do que os homens devido às diferenças inerentes aos sexos, talvez relacionado à "consciência viso-espacial" (Reason \& cols., 1990, p. 1330), e também pode ser explicado pelas diferenças no grau de envolvimento na tarefa de dirigir.

Pesquisas realizadas após Reason e cols. (1990) não acrescentaram significativas alterações no conhecimento sobre erros e violações, mas, por outro lado serviram para confirmar e fortalecer achados anteriores e aqueles encontrados em 1990 por estes autores. No estudo de Kontogiannis e cols. (2002), por exemplo, os autores consideram como interessante o fato de que os achados das pesquisas anteriores à sua, realizada na Grécia, fossem válidos mesmo para locais com condições diferentes daquelas verificadas na Inglaterra, Austrália e Suécia. Segundo os autores, as vias na Grécia são estreitas, há dificuldade de espaços para estacionamento adequado, má visibilidade dos sinais viários e diferentes condições socioculturais.

No Brasil, Sousa e Clark (2001) realizaram um estudo visando levantar a freqüência com que ocorrem os "erros, lapsos e infrações" (p. 302) e relacioná-los com o sexo e faixa etária dos motoristas. Foram aplicados 101 questionários DBQ a homens e mulheres de diferentes idades, moradores na Cidade do Rio de Janeiro e "os dados vão ao encontro de resultados obtidos em outros países" (Sousa \& Clark, 2001, p. 302). Segundo os autores, os resultados parecem indicar alguma relação com a falta de experiência, o excesso de autoconfiança e níveis de cautela diferen- tes em função do sexo e da idade do motorista. Muito embora Sousa e Clark (2001) afirmem que erros e lapsos estejam ligados à tomada de decisão e à atenção e que as infrações envolvem tanto fatores sociais quanto motivacionais, confirmando achados anteriores, fica subentendido pelo enunciado dos autores, salvo melhor interpretação, que erros e lapsos cometidos não são considerados por eles como infração, quando é sabido que estes atos inadequados às regras do trânsito estão no mesmo rol das demais infrações, conforme já foi descrito acima.

Após esta digressão na literatura, convencidos de que há diferenças entre erros e violações, retornamos ao foco principal deste artigo enfatizando duas conclusões do experimento de Reason e cols. (1990), as quais consideramos essenciais: 1) Erros e violações têm "origens psicológicas diversas que requerem diferentes maneiras de correção" e 2) Violações "requerem explicações relacionadas a fatores motivacionais e sociais, enquanto erros a características de processamento-informação do indivíduo" (p. 1315).

É muito difícil julgar se um determinado comportamento de motorista foi erro ou violação, devemos admitir, assim como é muito difícil também diagnosticar se o valor do dólar ou o índice da bolsa de valores variam em função de algum fenômeno político, da variação do preço do petróleo ou em decorrência do mercado. No entanto, economistas conseguem interpretar, na maioria das vezes, os fenômenos relativos ao assunto e em alguns casos conseguem interferir no comportamento das bolsas e do valor do dólar, dandolhes um tratamento adequado.

Profissionais e estudiosos das diversas áreas ligadas ao trânsito já demonstraram preocupação em relação ao tratamento dispensado aos que erram e violam as regras de trânsito, tanto no aspecto de diagnóstico como no de correção. Mas, se por um lado há esse progresso, pelo menos nas intenções e nas idéias, parece faltar muito ainda para que as velhas práticas, como, por exemplo, a de punir indiscriminadamente os que erram e os que violam, sejam erradicadas e substituídas por outras mais adequadas, racionais, lógicas e eficazes, de forma a prescreverem procedimentos diferenciados para os que erram e para os que violam. No caso dos que erram, os questionamentos e sugestões relacionam-se com uma educação de trânsito mais eficaz, de preferência incluída no Ensino Fundamental, no lugar de campanhas esporádicas, geralmente desencadeadas às vésperas de férias e feriados ou nas festivas Semanas do Trânsito, eventos que deveriam representar um papel acessório ou reforçador de um programa mais eficaz e sério. Questionamentos e sugestões também são endereçadas à avaliação psicológica de condutores de veículos. Alchieri (2003), após realizar uma pesquisa sobre a prática da avaliação psicológica de condutores no Brasil, con- 
cluiu que as críticas em relação à avaliação psicológica no trânsito não devem ser dirigidas aos instrumentos nela utilizados, mas na atuação profissional do psicólogo na escolha e no uso de instrumentos psicológicos, tarefas para as quais estariam despreparados.

Rozestraten (2000) obteve, no $37^{\circ}$ Congresso de Psicologia de Trânsito de Braunschweig na Alemanha, em 1998, informações sobre algumas inovações que vêm ocorrendo em Psicologia. Entre outros pontos observados, Rozestraten cita um equipamento informatizado acoplado a um simulador de direção veicular; psicoterapias, educação direcionada a condutores estressados e agressivos, enfim uma série de inovações importantes. Diante de tanta novidade observada naquele Congresso, Rozestraten questiona se o conhecimento psicológico não poderia fazer algo mais positivo para o homem brasileiro do que simplesmente testá-lo, para fins de obtenção da $\mathrm{CNH}-$ Carteira Nacional de Habilitação. Entendemos que o conhecimento psicológico poderia contribuir sim, como, por exemplo, desenvolver instrumentos para diagnosticar se os as infrações cometidas foram devidas a erros ou violações e também propiciar educação e ou terapias a essas pessoas, com objetivos específicos para cada caso.

As pessoas e as autoridades buscam melhores explicações e providências quanto ao absurdo número de mortos e feridos no trânsito e parecem não concordar que a participação da Psicologia no trânsito deva se restringir a um sim ou a um não no processo seletivo de condutores.

Não temos pronta uma solução prática para tornar viável a idéia de tratar adequadamente os que erram e os que violam. Entre as conclusões científicas e a sua prática existe um hiato que necessita ser trabalhado e muita resistência à mudança precisa ser vencida. As Câmaras Temáticas, onde o CFP - Conselho Federal de Psicologia - tem assento, ao lado de outros representantes dos diversos segmentos ligados ao trânsito, como Direito, Engenharia, Pedagogia, Medicina etc., parece ser o ambiente ideal onde a catálise desta relação entre a teoria e a prática pode acontecer, no nosso entender. O Jornal do Federal (Contran: Câmara Temática discute educação cidadã para o trânsito, 2004, dezembro) explica que as Câmaras Temáticas são órgãos técnicos vinculados ao Contran - Conselho Nacional de Trânsito - e têm como finalidade estudar e oferecer sugestões com embasamento técnico consistente sobre assuntos específicos para a tomada de decisões. O CFP participa da Câmara Temática de Cidadania e Educação e da Câmara Temática de Saúde e Meio Ambiente. Referindo-se a uma minuta de recomendações remetida do Contran ao Denatran Departamento Nacional de Trânsito, no que diz respeito ao PECT - Programa de Educação e Cidadania no Trânsito, Gislene Macedo, Conselheira do CFP, comenta no referido Jornal: "A proposta representa um avanço na questão da educação para o trânsito, já que integra conceitos emancipatórios de educação e cidadania. Nela a noção policialesca de educação parece estar sendo superada e espera-se que novas ações de educação para o trânsito sejam efetivadas, para que seus efeitos possam congregar valores que priorizem a vida humana". Nesta mesma matéria do Jornal é enfatizado que a Câmara Temática referida espera do Denatran "a garantia do respeito à diversidade rural, urbana, étnica, racial, de gênero e classe, no desenvolvimento das ações de formação, de capacitação e de campanhas...".

Visualizamos pelo menos alguns indícios nestas afirmações, que sugerem ser mesmo as Câmaras Temáticas o foro ideal para propostas mais específicas, de colocar em prática os resultados das pesquisas científicas, sinalizando que bons ventos possam estar soprando naqueles órgãos técnicos e sugerindo possibilidade de mudanças de ações nas relações autoridade-motorista. Por outro lado, as naturais resistências às mudanças existem, devidas a interesses diversos em jogo nestas questões sociais, como foi o caso da reivindicação de extinção do exame psicológico. Parte das declarações do Deputado Federal José Carlos Aleluia, do PFL-BA, resume as pressões exercidas, provavelmente por grupos de interesse, para o fim do exame psicológico: "O texto do Código Nacional de Trânsito aprovado pelo Congresso, ao estabelecer a obrigatoriedade da realização de exame de aptidão física e mental, não comete o exagero de detalhar o indispensável exame oftalmológico ou de, por exemplo, uma eventual investigação cardiológica. Pretenderam, no entanto, os congressistas especificar como incondicional o questionável exame psicológico" (Polêmica, 1997, dezembro). O Deputado ainda comentou que a decisão do presidente Fernando Henrique Cardoso, acaba com o faz-de-conta desses exames, "os quais fingem que examinam, em clínicas despreparadas, enquanto as autoridades de trânsito fingem que acreditam que os exames são para valer" (Polêmica, 1997, dezembro). Não fosse a intervenção eficaz do CFP nesta luta, os motoristas brasileiros estariam sendo hoje avaliados apenas sob o ponto de vista médico, o que possivelmente acarretaria menos saúde no trânsito. Por outro lado, na época da contenda em torno do veto presidencial, o CFP já reconhecia a necessidade de normatizar a utilização dos testes, mas, somente em 2003, a Resolução 002 regulamentou a elaboração, comercialização e o seu uso, pois "muitas ações judiciais eram impetradas, argüindo acerca da utilização e dos resultados de testes psicológicos" (Avaliação dos Testes Psicológicos, 2004, dezembro, p. 6). A análise dos testes, em condições de uso no país, foi reconhecida pelo Tribunal de Contas da União, afirma o CFP. 
Os velhos hábitos, mitos e interesses em torno da multa, por exemplo, precisam ser vencidos, mas somente com argumentações científicas e políticas convincentes estas barreiras cairão. Se, no entanto, as razões que levaram os grupos de interesses a tomarem tal decisão não forem esclarecidas e as providências tomadas, a participação da psicologia continuará a se restringir a aplicar testes e cursos a infratores que não levam em conta as pesquisas mais atuais e não contemplam, por exemplo, a distinção entre erros e violações.

Consagrados autores ligados à Análise do Comportamento, como Sidman (1995), têm sido defensores de práticas que priorizem o uso do reforçamento positivo ao invés de métodos coercitivos na vida das pessoas. Discorrendo sobre as diversas situações nas quais os seres humanos convivem com coerção, Sidman entra num assunto que nos interessa objetivamente, que é a relação das autoridades com os motoristas. Eis um trecho:

Atualmente, os policiais distribuem notificações de multas aos motoristas que são apanhados dirigindo em alta velocidade, ultrapassando sinal vermelho ou parada obrigatória, dirigindo sem usar o cinto de segurança, transportando crianças inadequadamente ou com lanternas e faróis defeituosos. O que aconteceria se, em vez disso, eles "apanhassem" os motoristas obedecendo os limites de velocidade, parando no sinal vermelho e em paradas obrigatórias, usando o cinto de segurança, transportando as crianças de forma segura ou com as luzes de sinalização do automóvel em perfeito estado e distribuíssem ingressos gratuitos para eventos esportivos, filmes, peças de teatro, concertos e museus? (Sidman, 1995, p. 272)

Sidman admite que o reforçamento positivo não funciona por magia, sendo simples em princípio, mas difícil de executar na prática, entretanto considera que esta inversão nos hábitos poderia não se mostrar impraticável como parece a princípio. Descreve também um detalhado roteiro que poderia ser seguido, caso a sua proposta fosse colocada em prática e nos conduz a imaginar com ele quais seriam os benéficos efeitos colaterais produzidos pela mudança: "Os carros de polícia não sinalizariam medo e apreensão, mas a antecipação de encontros amistosos e gratificantes, sinais bem-vindos de que tudo está bem” (p. 273).

Esta proposta de Sidman deve soar ousada demais, ou fantasiosa e ingênua por parte de muitas pessoas, em relação aos costumes, segundo os quais a punição é a melhor forma de corrigir comportamentos inadequados, embora a realidade mostre que as infrações continuam sendo cometidas em grande número, como é o caso de Belém do Pará, onde 79.201 foram registradas em 2001 (CTBel, 2001), correspondendo a cerca de uma infração para cada dois veículos. Este indicador pode significar a ineficácia da punição como uma medida única, com a finalidade de erradicar comportamentos inadequados, não significando esta afirmativa, entretanto, que maus condutores devam ficar impunes.

A história tem mostrado que grandes mudanças provocam, de fato, grandes resistências e também transtornos iniciais, mas também tem evidenciado que vale a pena modificar um estado de coisas quando este não é justo e bom, como é o caso aqui tratado, mesmo havendo consciência dos riscos e das dificuldades da mudança.

Mattaini (2002, p. 397) sugere que deve ser dada atenção a quatro áreas nas ações orientadas para o tratamento de questões sociais:

1) Envolver políticos, formadores de opinião e cidadãos com imagem sociopolítica reconhecida; 2) Esclarecer classes de atores para implementar intervenções a nível de comunidade; 3) Examinar obstáculos que possam interferir com estes direcionamentos estratégicos e suas resoluções; 4) Discutir a importância crucial de se ensinar análise do comportamento, porque uma substancial estrutura de profissionais bem treinados e um público bem educado será requerido se a efetiva intervenção em questão ocorrer.

Nas ruas, avenidas e estradas brasileiras, a todo momento, é fácil observar exemplos dos achados da pesquisa de Reason e cols. (1990), onde são visíveis as violações ao trânsito e visível também é o cenário social onde estas ações se realizam, ou seja, uma perfeita relação entre violação e o contexto social.

No momento em que este artigo é escrito, um clima de violência grassa no Brasil, oriundo de graves problemas sociais acumulados e não solucionados ao longo do tempo, principalmente nos grandes centros urbanos, como o Rio de Janeiro, onde certas regras da boa convivência entre pessoas, inclusive no trânsito, são subvertidas. Um sintoma deste mal, por exemplo, está representado na consciência coletiva do motorista brasileiro que procura justificar o avanço do sinal vermelho como algo necessário para a sua sobrevivência aos assaltos praticados nos cruzamentos viários. Além destes, outros fatos denunciam grave crise moral e social, refletida também no trânsito, como por exemplo o que observamos pessoalmente dirigindo veículo na cidade do Rio de Janeiro, em janeiro de 2004. Constatamos, além dos inúmeros avanços de sinal praticados, um costume de alguns motoristas pressionando, com buzina e/ou farol, aqueles que estavam corretamente parados à sua frente aguardando a abertura de sinal, como se eles estivessem burlando alguma norma informal estabelecida. Em cidades onde a população e a frota de veículos são bem meno- 
res do que as do Rio de Janeiro, este fato já é observado ainda que com menor freqüência, fazendo supor que essa prática esteja tornando-se nacional.

Estes fatos nos sugerem, com base na Teoria dos Valores de Schwartz (2001), a existência de conflitos de valores em que os tipos motivacionais conformidade, tradição e segurança colidem com estimulação e auto-direção, que em uma escala mais ampla de Schwartz (2001, p. 59) seria o conflito entre a conservação (das normas de trânsito e da ordem) e a abertura à mudança (para a desordem e o não cumprimento das normas de trânsito).

Um dos fatores responsáveis pelo incremento da violência é a deterioração dos centros urbanos, em decorrência dos efeitos negativos provocados por más administrações governamentais e agravados pela crise econômica mundial, com decorrentes superpopulação, desemprego e violência. Muitos administradores municipais brasileiros parecem impotentes diante de problemas que extrapolam suas competências, como é o caso do desemprego, responsável pelo excessivo número de vendedores informais que atravancam o trânsito, como ocorre em muitas cidades brasileiras. Cardoso (2002), citando Unchs (1996), mostra que o problema da superpopulação urbana é um fenômeno que vem ocorrendo na maioria das cidades do Planeta nesta virada do século, quando a população cresce à taxa de 60 milhões de pessoas a cada ano e "evidências mostram que elas estão e estarão concentradas em cidades de países em desenvolvimento" (Cardoso, 2002, p. 35).

A propósito desta discussão, e a título de reflexão sobre a influência do contexto social como responsável pela violação, vale citar aqui uma pesquisa realizada em Tel Aviv, Israel, em cruzamentos com semáforos. Yinon e Levian (1988), verificaram que os avanços ao sinal vermelho aconteciam com mais freqüência quando havia mais de um veículo parado no cruzamento, aguardando o sinal verde. Os pesquisadores concluíram que o comportamento observado se relacionava com alguma necessidade de disputa entre os condutores. Conjeturamos se este comportamento competitivo observado naquela cidade poderia ter sido influenciado pelo permanente clima beligerante, advindo das eternas disputas territoriais naquela região e questionamos: Esta necessidade de disputa observada nos motoristas israelenses, em última análise, não seria motivada também pelo fator segurança, por exemplo? Nesse aspecto parece haver relação entre o Brasil e Israel no que se refere à motivação segurança, mas com uma diferença, porque lá a segurança é relacionada à guerra constante pela disputa do território, dos ódios raciais, e no Brasil às condições socioeconômicas advindas de outras questões.
Um outro fator a considerar na busca do entendimento do comportamento do motorista é a impunidade, que parece ser um propulsor poderoso para o não cumprimento das normas. Numa pesquisa realizada em quatro cruzamentos semaforizados de Belém do Pará, onde em dois destes locais o motorista tinha visão da via e dos outros veículos que cruzavam com aquela via onde estava aguardando a abertura do sinal, houve mais avanços do que em dois outros locais onde não era possível realizar esse controle visual. Foram observados 32.698 veículos motorizados e 585 avanços de sinal, sendo que nos locais de melhor visibilidade e com menor probabilidade da presença de agentes de trânsito houve $91,21 \%$ dos avanços, correspondente a 510 veículos. Rocha (2001) concluiu que a visibilidade facilitou o avanço, dentre outros vários fatores facilitadores inerentes ao nosso trânsito, mas acredita que em última análise a impunidade teria sido a maior responsável pelo abuso. Interessante notar que no outro local de grande visibilidade no centro da cidade, onde havia maior probabilidade da presença de agentes do trânsito e onde havia intenso tráfego, aconteceram apenas 24 avanços $(4,10 \%)$, fato que fortaleceu ainda mais a crença na impunidade como principal responsável pelos avanços.

\section{CONCLUSÃO}

A engenharia tem dotado os veículos de formidáveis avanços tecnológicos e equipado as vias com sofisticados recursos (onde os governos permitem), com a preocupação de proporcionar melhores condições de fluxo e segurança da crescente frota de veículos e dos usuários do trânsito. Por outro lado, a reflexão em torno dos erros e violações no trânsito e das variáveis que os antecedem, determinam ou influenciam, vêm ganhando felizmente maior dimensão nos debates entre os estudiosos, mas, as pesquisas e os avanços técnicos nas questões comportamentais no trânsito, entretanto, quando comparados aos avanços tecnológicos de equipamentos e veículos não acontecem na mesma velocidade devido às naturais resistências humanas e à própria natureza do assunto, descompasso este também responsável talvez pelas dificuldades do trânsito nas grandes cidades, ao lado de outros problemas sociais.

No quadro geral de problemas de trânsito, a necessidade de se distinguir erros de violações, para que seja dispensado melhor tratamento aos motoristas que erram e violam, poderá possibilitar a administração de "medicamentos" mais específicos, capacitando-os e adequando-os ao meio viário com medidas corretivas mais justas e eficazes que possam, de fato, contribuir para uma melhor participação desses motoristas no trânsito. 


\section{REFERÊNCIAS}

Aberg, L. \& Rimmo, P. A. (1998). Dimensions of aberrant driver behaviour. Ergonomics, 41, 39-56.

Alchieri, J. C. (2003). Considerações sobre a prática da avaliação psicológica de condutores no Brasil. Em M. H. Hoffmann, R. M. Cruz \& J. C. Alchieri (Orgs.), Comportamento humano no trânsito (pp. 251-261). São Paulo: Casa do Psicólogo.

Avaliação dos Testes Psicológicos (2004, dezembro). Jornal do Conselho Federal de Psicologia, encarte especial, p. 6.

Blockey, P. N. \& Hartley, L. R. (1995). Aberrant driving behaviour: errors and violations. Ergonomics, 38, 1759-1771.

Cardoso, A. C. D. (2002). The alternative space: informal settlements and life chances in Belém, Brazil. Tese de doutorado, School of Architeture, Oxford Brookes University, Inglaterra.

CTBel (2001). Mensagem à Câmara Municipal de Belém: Relatório de atividades de 2001. Belém: Companhia de Transportes do Município de Belém.

Contran: Câmara Temática discute educação cidadã para o trânsito. (2004, dezembro). Jornal do Federal. Conselho Federal de Psicologia, p. 7.

Kontogiannis, T., Kossiavelou, Z. \& Marmaras, N. (2002). Self reports of aberrant behaviour on the roads: errors and violations in a sample of Greek drivers. Accident Analysis \& Prevention, 3, 381-399.

Mattaini, M. A. (2002). Acting to save the world: the elements of action. Em M. Mattaini \& B. A. Thyer (Orgs.), Finding solutions to social problems: behavioral strategies for change (pp. 397-414). Washington: American Psychological Association.

Monteiro, C. A. S. (2004). Variáveis antecedentes de erros $e$ violações de motoristas. Tese de Doutorado. Universidade de Brasília, Brasília.

Parker, D., Reason J. T., Manstead, A. S. R. \& Stradling, S. G. (1995). Driving errors, driving violations and accident involvement. Ergonomics, 38, 1036-1048.

Polêmica (1997, dezembro). FHC fez bem em vetar o psicotécnico para motoristas. Istoé 1466, Seção Polêmica. Obtido em 15 de fevereiro de 2005 do World Wide Web: http://www.terra. com.br/istoe/polemica/146601.htm.7k.

Reason, J., Manstead, A., Stradling, S., Baxter, J. \& Campbell, K. (1990). Errors and violations on the roads: a real distinction? Ergonomics, 33, 1315-1332.

Rocha, J. B. A. (2001) O avanço do sinal vermelho nos cruzamentos de Belém. Arquivos Brasileiros de Psicologia, 53, 3441.

Rozestraten, R. J. A. (2000). Novos caminhos para a Psicologia do Trânsito. Psicologia Ciência e Profissão, 4, 80-85.

Schwartz, S. H. (2001). ¿Existen aspectos universales en la estructura y contenido de los valores humanos? Em M. Ros, V. V. Gouveia (Orgs.), Psicología social de los valores humanos: desarrollos teóricos, metodológicos y aplicados (pp. 53-77). Madrid: Editorial Biblioteca Nueva.

Sidman, M. (1995). Coerção e suas implicações. São Paulo: Editorial Psy.

Sousa, L. M. Clark, C. (2001). Erros, lapsos e infrações no trânsito. Sociedade Brasileira de Psicologia. Resumos de Comunicações Científicas da XXXI Reunião Anual de Psicologia da SBP. Rio de Janeiro: SBP.

Storie, V. J. (1977). Male and female car drivers: differences observed in accidents. TRRL Report 761 (TRRL, Crowthorne).

Westerman, S. J. \& Aigney, D. (2000). Individual differences in driver stress, error and violation. Personality and Individual Differences, 29, 981-998.

Yinon, Y. \& Levian, E. (1988). Presence of other drivers as a determinant of traffic violations. Em T. Rothengatter e R. Bruin (Orgs.), Road user behavior: theory and research (pp. 274-27). Wolfeboro, USA: Vam Gorcum.

Enviado: 02/06/2004

$1^{a}$ Revisão: 03/01/2005

$2^{a}$ Revisão: $28 / 02 / 2005$

Aceito: 10/06/2005

\section{Sobre o autor:}

João Bosco de Assis Rocha: Mestre em Psicologia:Teoria e Pesquisa do Comportamento pela Universidade Federal do Pará e Doutorando em Psicologia; Professor da UFPA - Endereço eletrônico: bosco@ufpa.br. 
